\title{
Making Space. Singapore, Artists \& Art in the Public Realm
}

\author{
Sharmila Wood \\ Tarruru, Australia \\ sharmila@tarruru.com.au
}

\begin{abstract}
In recent times Singaporean artists have undertaken audacious artistic performances, actions and interventions in public space, highlighting the role of artists as provocateurs of debates around public space and their engagement with issues related to ethical urbanism. Between 2010 - 2020 artists working in diverse fields of artistic practice including visual art, street art, performance art, community arts and new genre public art begun to locate their artwork in public spaces, reaching new audiences whilst forging new conversations about access, inclusion and foregrounding issues around spatial justice. In contesting public space, artists have centralized citizens in a collective discourse around building and shaping the nation. The essay documents key projects, artists and organisations undertaking artistic responses in everyday places and examines the possibility of public art in expanding concepts of 'the public' through actions in Singapore's public space, and demonstrating the role of artists in civil society.
\end{abstract}

Keywords: public art, public space, community empowerment, creative intervention, ethical urbanism, spatial justice, social engagement

To cite this article:

Wood, S. (2020) Making Space. Singapore, Artists \& Art in the Public Realm, The Journal of Public Space, 5(4), I37-I54, DOI I0.3289I/jps.v5i4.I408

This article has been double blind peer reviewed and accepted for publication in The Journal of Public Space.

(c) (1) \$ This work is licensed under a Creative Commons Attribution - Non Commercial 4.0 International License https://creativecommons.org/licenses/by-nc/4.0/ 
In recent times, a number of young Singaporean artists have undertaken audacious artistic performances, actions and interventions in public space, highlighting the role of artists as provocateurs in catalyzing discussions about the politics of space, and the role of art in civil society. Making Space: Singapore, Artists \& Art in the Public Realm documents artistic projects over the decade from 2010 - 2020 through interviews and field research conducted during an Asialink curatorial residency in Singapore. The artistic projects outlined in the essay include diverse and democratic approaches including theatre, artistic interventions and programming by arts organizations. These initiatives are united by their engagement with public space as a way to raise questions, concerns and disrupt hegemonic politics through artistic praxis. The French Philosopher Jacques Ranciere in Dissensus: On Politics and Aesthetics argues that dissensus suspends the 'naturalness' of the rules that govern art the way cities are produced and ordered. (Ranciere, 2010) The potential of aesthetics to affect the perception of the sensible creates new meaning and spaces emerges as a method to critique the commercialization of public squares and plazas, and the rezoning, and demolition of public space, heritage places, and sometimes, people's homes.

Whilst Singapore boasts an impressive collection of public art works, including commissions by leading international artists such as Anish Kapoor, Henry Moore and Fernando Botero, these monumental pieces are mainly relegated to traditional zones for public art such as corporate or retail environments in the business and commerce district of Singapore. In contrast, many of the artists highlighted in this essay have created public art interventions located in everyday spaces such as Housing Development Board (HDB) blocks. Artwork in Singapore's so-called 'Heartlands' (concentrated areas of public housing) reflects the role of art as an act of citizenship that provokes questions of belonging, place, heritage, and identity. As artwork transcends the confines of the gallery, and the concept of public art moves beyond sculptural works to artists collaborating with citizens to critique and activate their urban environment, public art offers possibilities for participatory action. The interaction, and spontaneity of these activities adds vibrancy to the everyday urban environment and is an appealing option for positive engagement with art.

There are approximately 10,000 HDB blocks on Singapore Island that accommodate over eighty five percent of the population. The public housing model was established in the 1960's in response to the need for low-cost housing to accommodate a growing population. Today, HDB apartments are the primary housing options, with blocks of apartments and ground floor public space environments familiar to the majority of Singaporean residents. HDB are governed by protocols that regulate the use of space and the surrounding environment, including personal expression inside shared spaces such as corridors, staircases, and void decks are ubiquitous vacant ground floors of Housing Development Board apartments, which are designated for communal activities, and sometimes include small provision shops.

They are used for functions, weddings, funerals, and other ceremonies as well as informal spaces for socialising. Artists and arts organizations are increasingly engaged with the HDB environment with activities that highlight the common ownership of these spaces. The interest in engaging with the HDB as public space for civic debate is reflected in the widespread public interest in Priyageetha Dia's Golden Staircase (2017), which stirred a mainstream response to notions of shared spaces in the HDB environment. (Chang, 2020, p.I). 


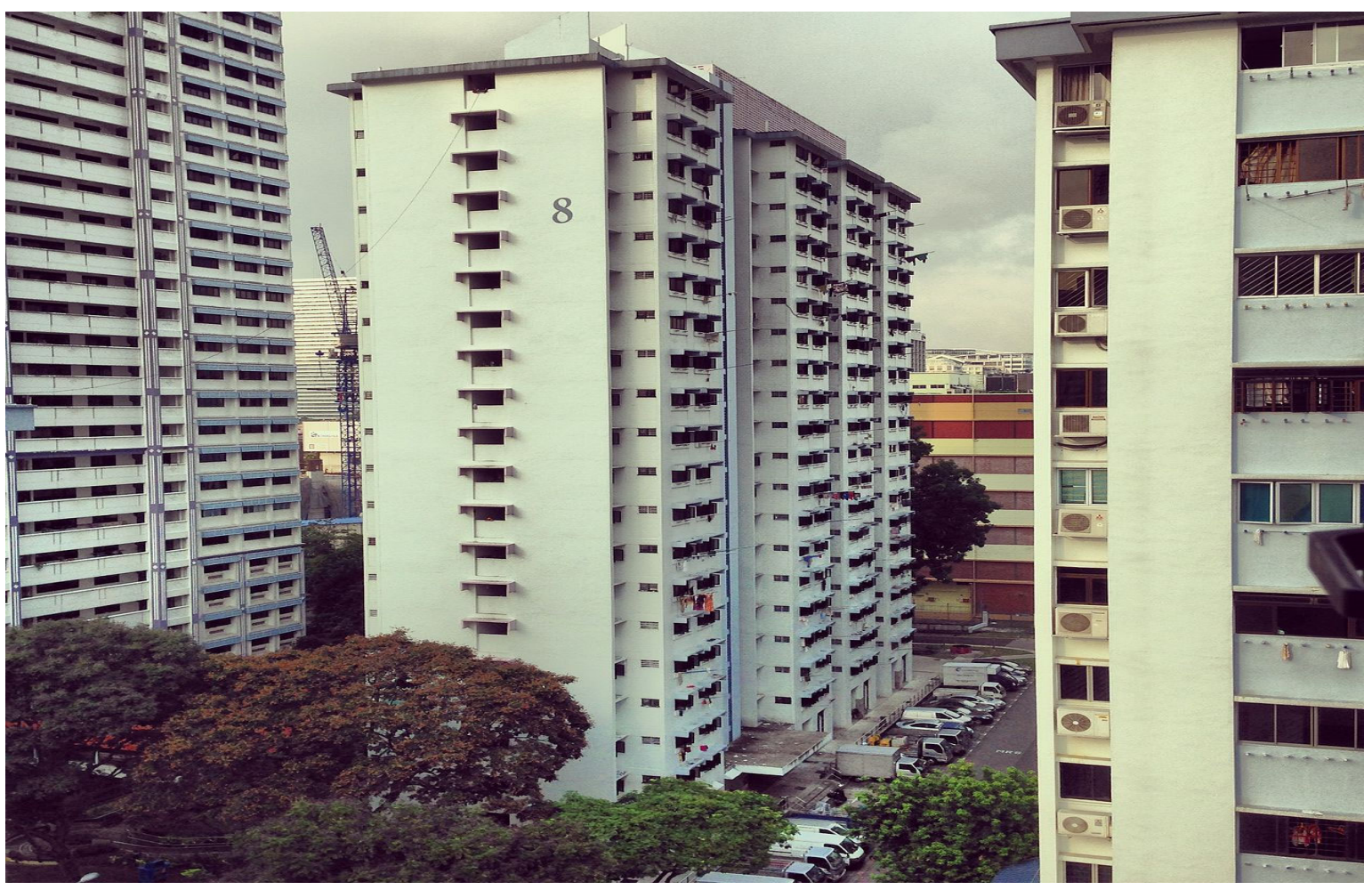

Figure I. Martin Pasquier, A view of Housing and Development Board (HDB) flats in Lavender, Singapore, seen from Block 805, King George's Avenue, 2014.

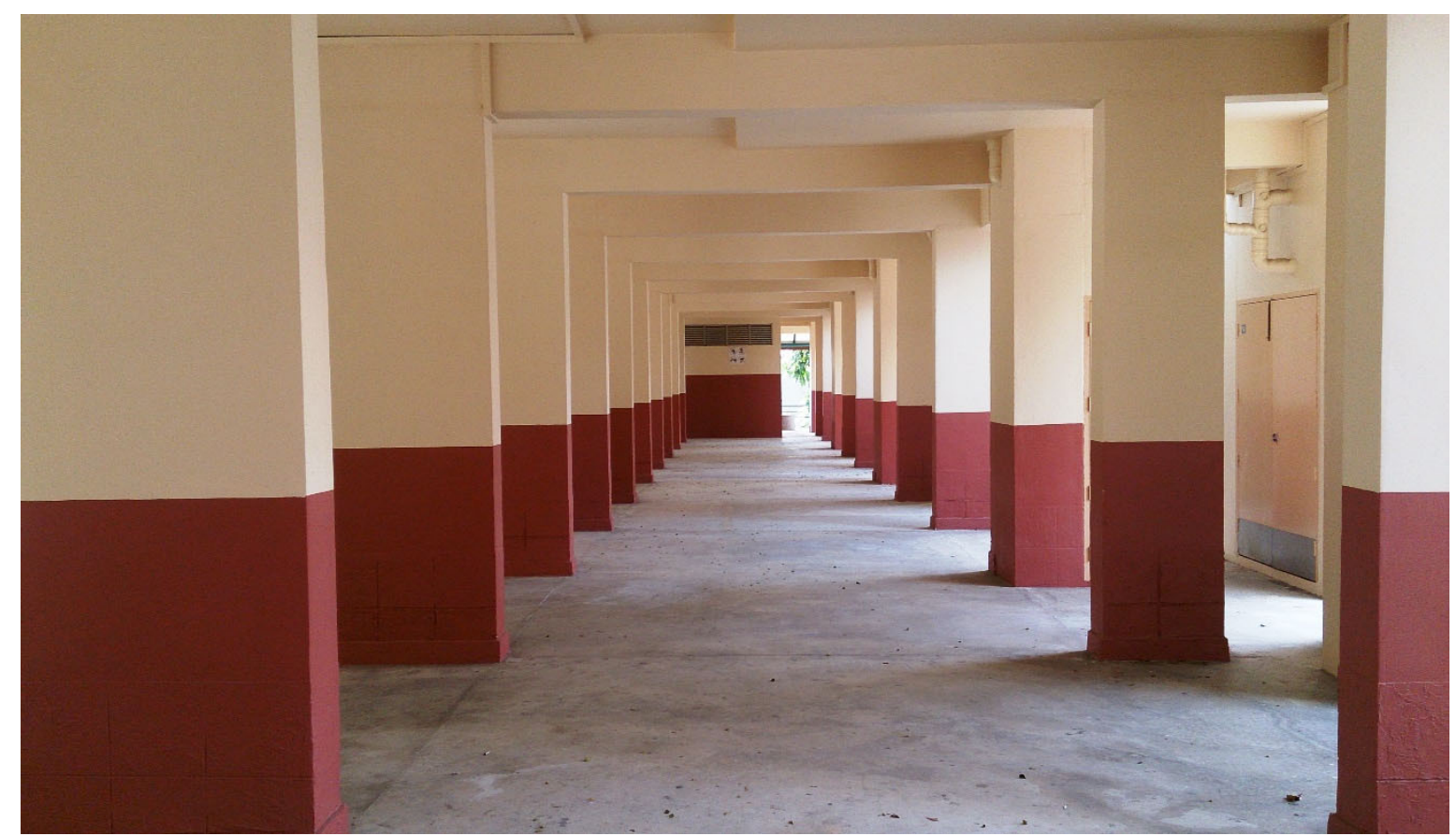

Figure 2. Project Manhatten The void deck of a block of Housing and Development Board (HDB) flats, 2014. 
For Golden Staircase Dia applied 400 sheets of delicate, chiffon thin 2 I karat gold paper to an eight- step staircase in the Jalan Besar HDB apartment block, where she was raised. Dia performed this artistic intervention with some trepidation 'The process was an invigorating one though I was apprehensive of the consequences I may face,' Dia states (Dia, 20l8). 'At the end of the five-hour long hushed deed, the intervention of the gold finally reverberated against the ever lifeless and grey architecture on the 20th floor of my block,' she explained. (Dia, 2018). In photographs that capture Dia's completed artwork, the gold has a radiant, sensuous quality. The juxtaposition of this material against the concrete staircase and walls creates an immediate impact as Dia's artistic intervention shines with presence and beauty. This charismatic artwork emerged from her identity as both a resident and an artist. Her personal identification and intimate understanding of HDB spaces reinforced questions about individual autonomy over shared public space, whilst in her role as an artist Dia raised questions about who has the right to alter, change, and design public space. In doing so, Dia asserted a sense of ownership over public space that regenerated her.

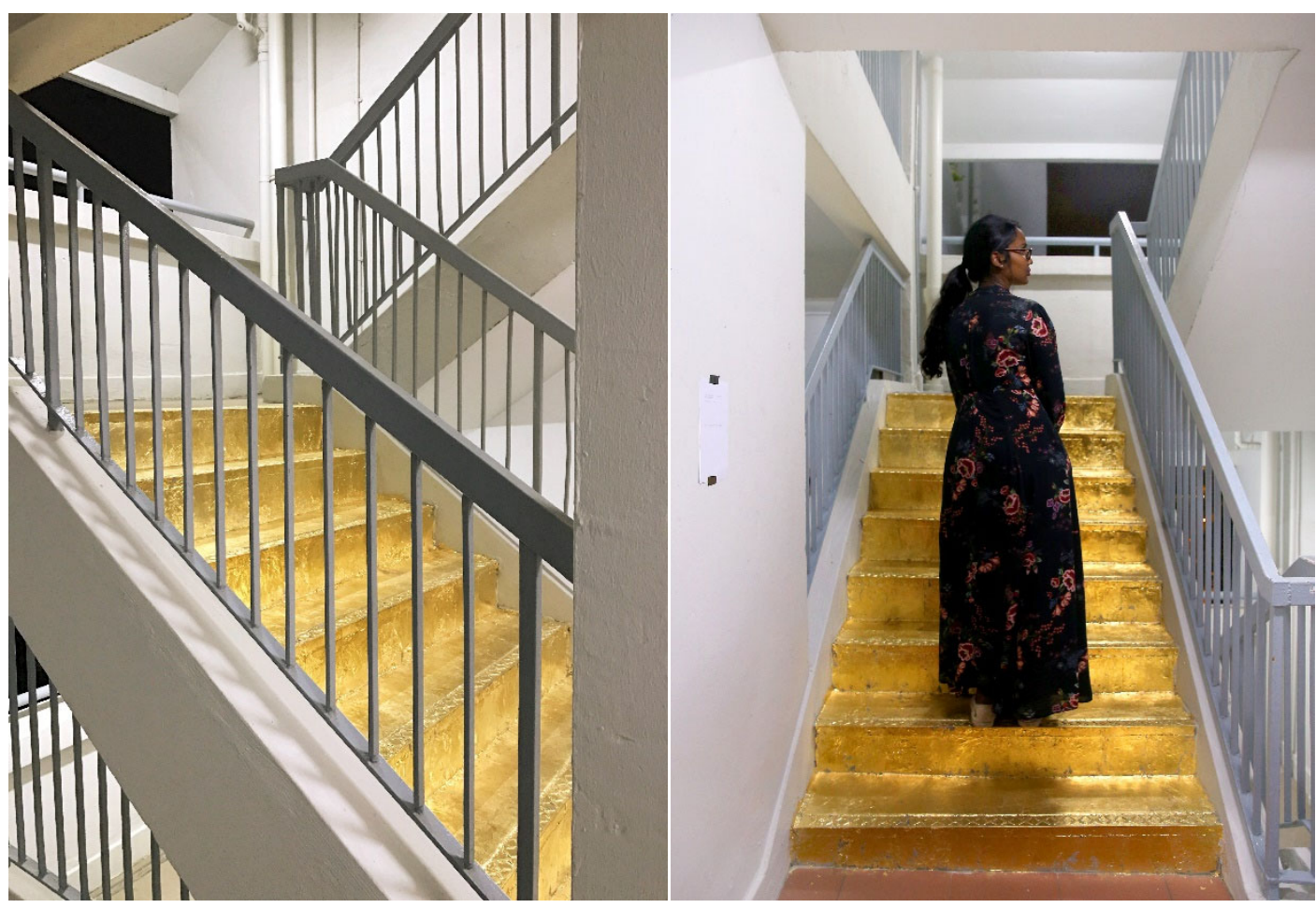

Figure 3. Priyageetha Dia The Golden Staircase, 2017.

The transformation of a staircase which is a vernacular site in the HDB provoked the widespread general public engagement as a familiar context transformed through an artistic context. The circulation of the image was facilitated through the platform of social media, rather than an exhibition format, highlighting the intersection of physical and the online pubic realms. The democratization of the art intervention created a range of engagement with the artwork after Dia's neighbor took a photograph and posted an image of Golden Staircase on social media. The anonymous user name pm_me_your_kukujiao appeared on REDDIT, the social news and discussion site, posing the question: Why did someone cover these stairs in gold foil? (Dia, 2018). In the 
networked and urbanized city-state, the online interest was rapid and within hours a debate had escalated about whether Golden Staircase was art or vandalism, and a range of threads that questioned the artists' motivation, and rationale. The responses ranged from vitriolic and violent threats to the artist, as well as praise for the intervention. Ultimately, Golden Staircase raised questions about what kind of freedoms for personal creative expression should exist in the HDB environment and revealed how multiple histories, identities and desires converge in the shared public spaces of the HBD environment.

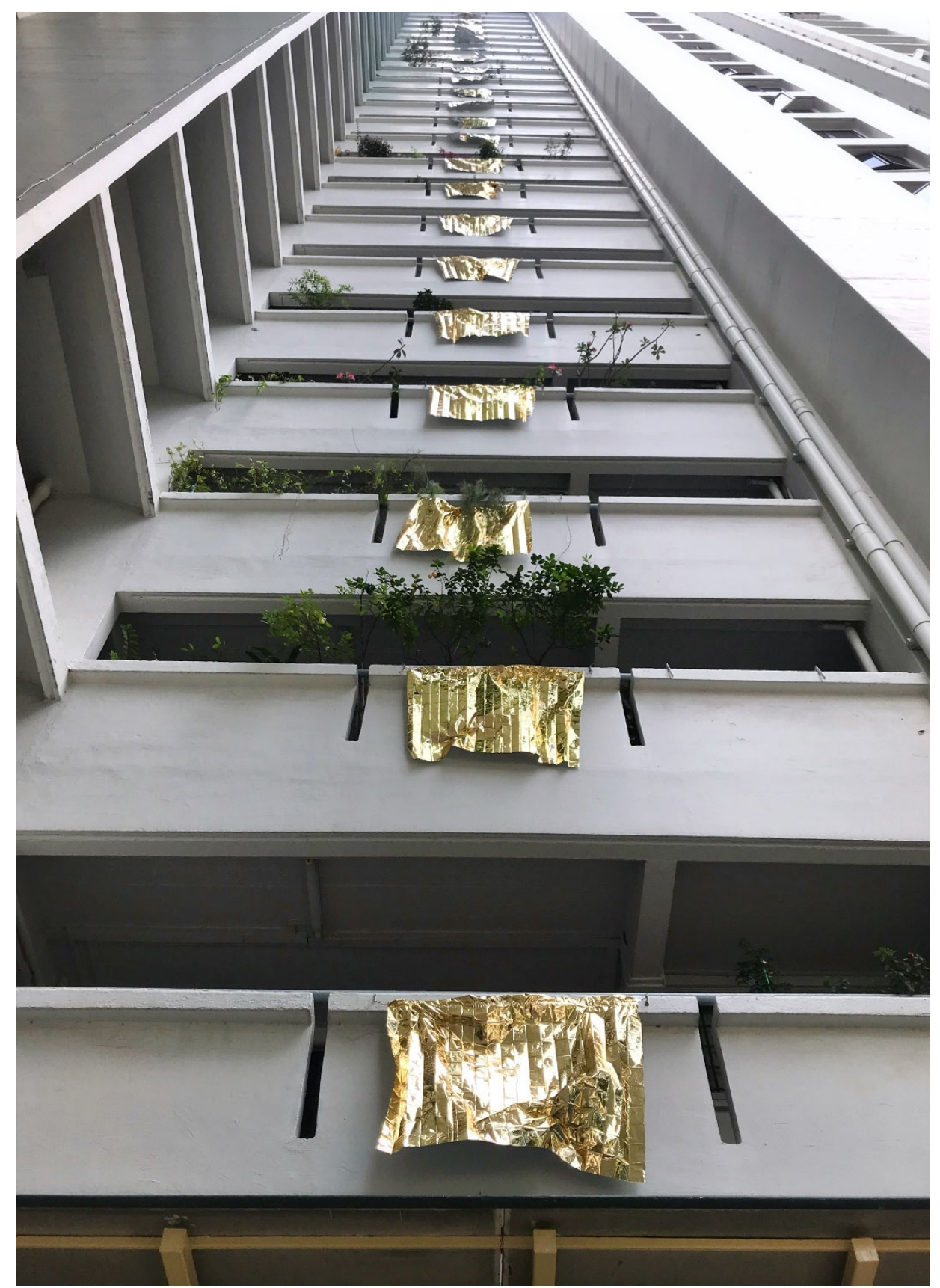

Figure 4. Priyageetha Dia Absent - Present, 2018. 
The Golden Staircase effectively highlighted how the internet and social media can animate and enliven civic concerns demonstrating its potential to expand audiences for artwork, and the range of people engaging with political issues raised by effective public art interventions. The relative anonymity offered by these platforms empowered citizens to assert their views and opinions on a range of issues, including the ownership of public space in HDB apartments. Singaporean Architect, Professor William S.W. Lim, founder of the Asian Urban Lab advocated for online mass communication as an inclusive platform for promoting spatial justice and amplifying conversations around ethical urbanism in the development of the city-state. As Lim writes in Public Space in Urban Asia the inter-net is a way for citizens to actively participate in how public space is shaped, and to reimagine public space in Singapore (Lim 20I4, pp. 240 - 24I). 'The struggle over geography and place is not new to Singapore, 'Lim writes. 'It is just that the Internet has made it harder to ignore the voices of those who are embracing their right to shape the environment they live and work in and those who recognise the value of conservation and the necessity of sustainability. This has resulted in renewed vigour in urban spatial contestations. Contestations of public spaces should not be viewed as antagonistic anti-establishment actions but opportunities for ordinary citizens to present alternatives as stakeholders. The sense of common ownership is enhanced when citizens become responsible for crafting the use of public space.'

The Jalan Basar Town Council, the body responsible for managing her HDB block made a statement that Dia's act was not permissible and commanded its removal, whilst also acknowledging her desire to enhance her surroundings. 'Eventually, I removed the work, as a voluntary act in the middle of the night,' Dia recalled (Dia, 2018). 'My arms ached for the next few days. I did it at 2am because I didn't want the media people to document me removing the work, because I found it to be such a depressing act, going from gold to grey.' (Dia,20 I8). Dia left a tiny gold square as a memory of her intervention in public space, and has followed up this first artistic action with another intervention in her Jalan Basar HDB apartment block with her installation work, Golden Flags (2018) in which she placed golden mylar blankets on each level of the Singapore National Day flag hooks for each level of her 24 story HDB to create a glimmering and kinetic installation. This artwork was not permissible and Dia removed the flags following criticism from the local municipal government. Yet, once again, Dia had produced a temporary liminal space through a public art intervention, asserting that public space can bee fluid, dynamic, and contestable rather than a space that is fixed, immovable and irrefutable. Dia's series of art interventions highlighted a desire for visibility, and the complexity of identity for citizens of HBD apartments in which the politics of private and public space are contested.

In seeking to manage and provide a governance structure for artists who pursue temporary artistic interventions the Singapore government developed a framework for artists wishing to create works in public spaces under The Public Art Trust (PAT) initiative established in 2014. PAT provides funds to generate new public artworks through commissioning and presentation opportunities through two programmes. The 'Public Spaces for Art' and 'Practice Spaces for Street Art', provide a 'preapproved list of 49 spaces for temporary artworks for artists who want to explore ideas for the public realm.' (PAT, 2019). Zong Qi Koh commented in Spacing Beyond the Lines: Graffiti's Place in the Singapore City State, that managing the activities of street art through urban planning is a strategy of containment and a way to control subversive activities 
through bureaucratic regulation (Zong Qi 2018) 'In a nation that prides itself on being clean and green, graffiti has traditionally been seen as intrusive, disrupting the pristine and organized aesthetics of his urban city, and urban planning has been a means of controlling and even eliminating it.' Whilst rules around graffiti ensure the prohibition of illegal street art, the opportunity to create artwork in public spaces continues to operate as an emancipatory gesture, mobilizing dissensus as a tool to critically reflect on how citizens interact and engage with everyday spaces. In Singapore, artists are embracing their role in contribuiting to improving the urban environment through opportunities fo rcreative expression in public space that can enhance the everyday environment for ordinary citizens.

Whilst most Singaporean street artists maintain legal activity, there have been artists such as SKLO or Samantha Lo, commonly referred to as Sticker Lady who have transgressed the legal limits of creative expression in public space.

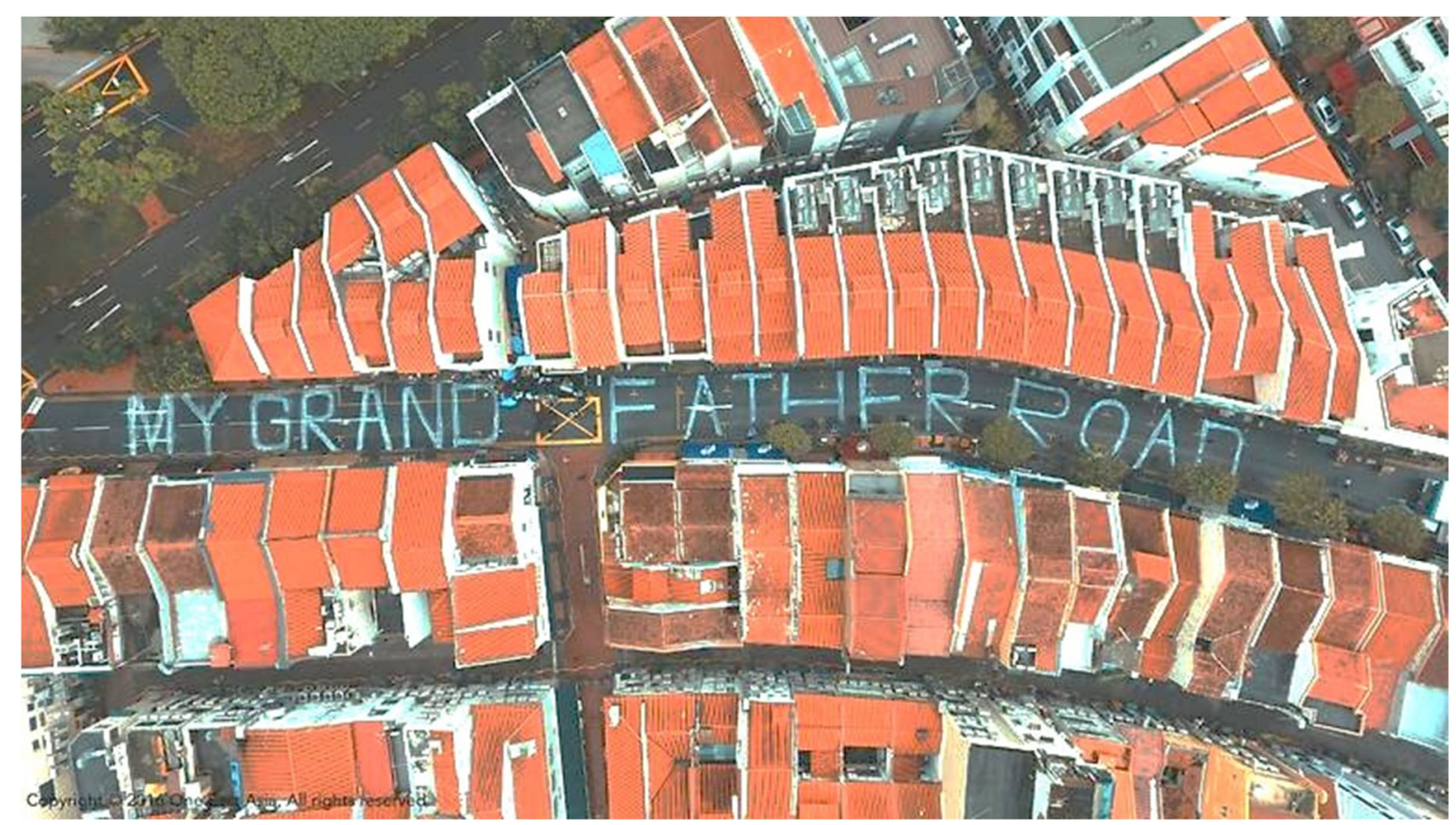

Figure 5. Samantha Lo, My Grandfather Road, Circular Road for Circular Spectacular, 2016.

In 2012, Samantha Lo was arrested for vandalism and charged for mischief after spray painting a public road, as part of her Champion Colloquial project. The project was conceptualised as a way to assert a distinctively Singaporean identity on the city landscape through direct intervention. SKLO has closely aligned her aesthetics and visual references with international street art and draws from the visual signifiers of punk culture to represent an act of protest. She spray-painted the words 'My Grandfather Road' on a number of roads around Singapore, and pasted stickers on various pedestrian crossing buttons, CCTV cameras and bins with humorous satirical phrases such as, 'Press for Nirvana' and Press Once Can Already'. In selecting these public locations, Lo directly tackled tensions between development and heritage, identity and belonging with her homage to 'Singlish'. 
The PAT Initiative was launched two years after Lo's arrest and since this time, she has completed a 170 metre long 'My Grandfather's Road' piece along Singapore's Circular Road commissioned by Singaporean arts organization Hyphen Arts. The piece mimics the original artwork for which she was arrested and demonstrates policy reform that facilities opportunities for artists to be engaged with active participation in the transformation of public space that resonates with a distinctively Singaporean narrative and sense of place. Rather than being viewed as threatening or negative acts of guerilla art, these artists can make meaningful contributions to the formation of identity and the progress of the nation state. Lo is regularly engaged by the Singapore Government to participate in arts festivals to perform activities for which she had originally been arrested. Government policy frameworks such as PAT re-contextualizes the spatial politics around public artwork and demonstrates how disobedience and subversion are channeled into the development of creative spaces around the city where artist's activities receive government funding and resources, amplifying their voices in the urban environment.

The methodologies and strategies of visual art interventions in public space are distinctive from the artist Seelan Palay, who was jailed in January 2019. Palay's charge was not for performing an illegal artwork but rather, for partaking in a public procession without a permit as result of his performance art piece. The charge resulted from his October 2017 performance art piece, 32 Years: The Interrogation of a Mirror (Performance with paint marker on mirror, three books, investigation letter, heat engraving on acrylic sheet, and acrylic on cotton). The performance was a tribute to Chia Thye Poh. According to Amnesty International Poh is Singapore's longest serving political prisoner (Amnesty International, 1998). 'Chia Thye Poh, a former Member of Parliament representing the opposition Barisan Sosialis (Socialist Front - a breakaway faction of the PAP), was arrested on 28 October 1966 for participating in demonstrations and strikes. He was detained for twenty-three years without trial under the ISA (Internal Security Act). On his release in 1989 Chia Thye Poh was placed under restriction orders curtailing his freedom of movement, expression and association, in order to "prevent him from acting in any manner prejudicial to the security of Singapore".' Poh has been a subject of Palay's previous 2013 work, which mimicked a missing persons poster and read 'MISSING YOU'. Palay printed 200, A4 photocopied flyers that he has distributed.

Although Palay studied painting with drawing his preferred medium, the performance genre provided a purposeful approach to an activist art statement. Performance art is politicized in Singapore due to its history as a form of protest stemming from Joseph Ng's performance Brother Cane, performed at Artists' General Assembly at 5th Passage, Parkway Parade, Singapore. The work was undertaken on $I^{\text {st }}$ January 1994 as a comment on the arrest and caning of twelve homosexual men. $\mathrm{Ng}$ snipped his pubic hair before a small audience as a symbolic protest and was fined $\$ 1,000$ for committing an obscene act, and prohibited from future public performances. Brother Cane led to a 10 - year restriction on the licensing and funding of performance art in Singapore ( $M$. Wong, 2016). 


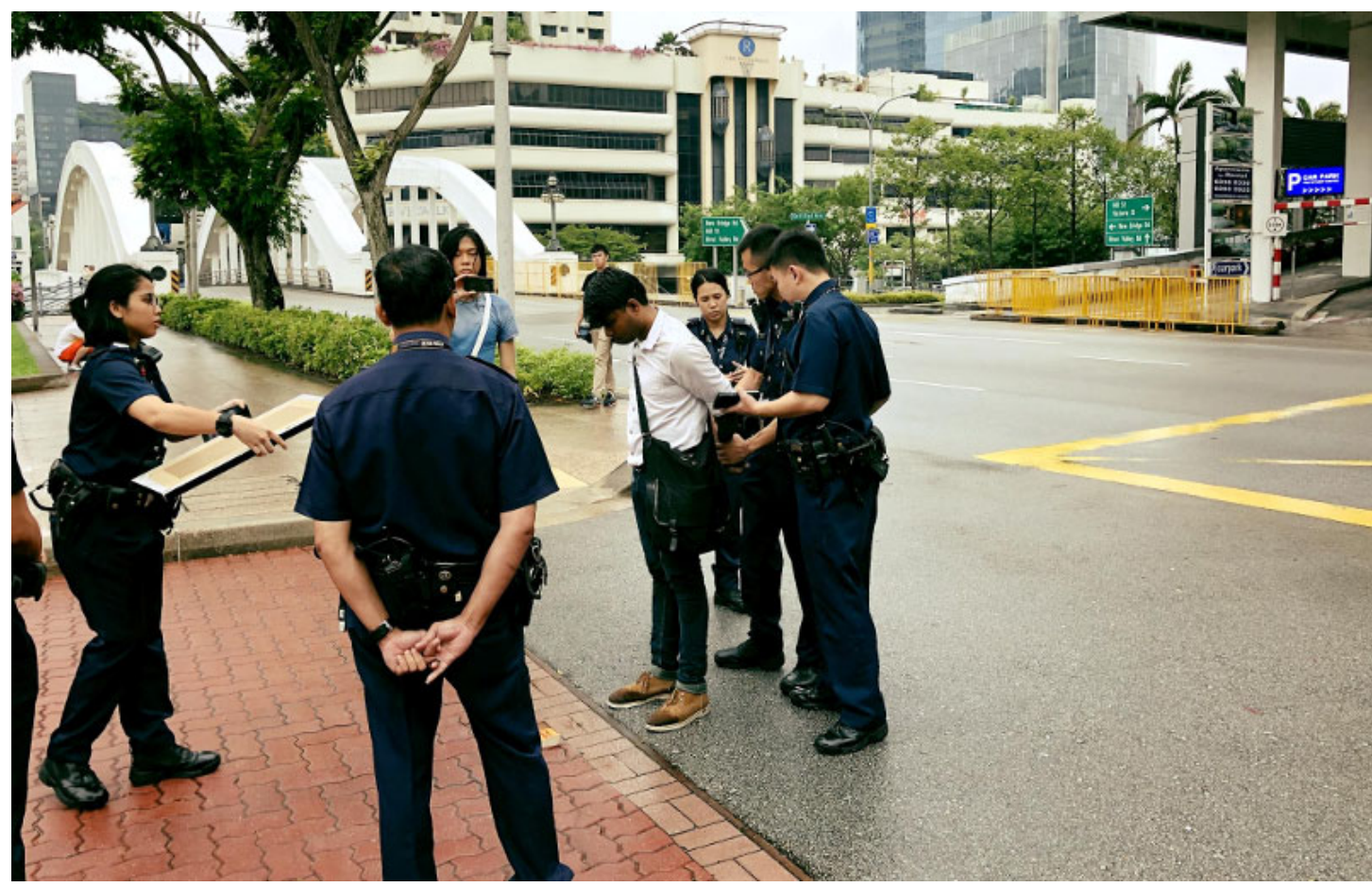

Figure 6. Courtesy, Seelan Palay being arrested during his performance 32 Years, The Interrogation of a Mirror 2019

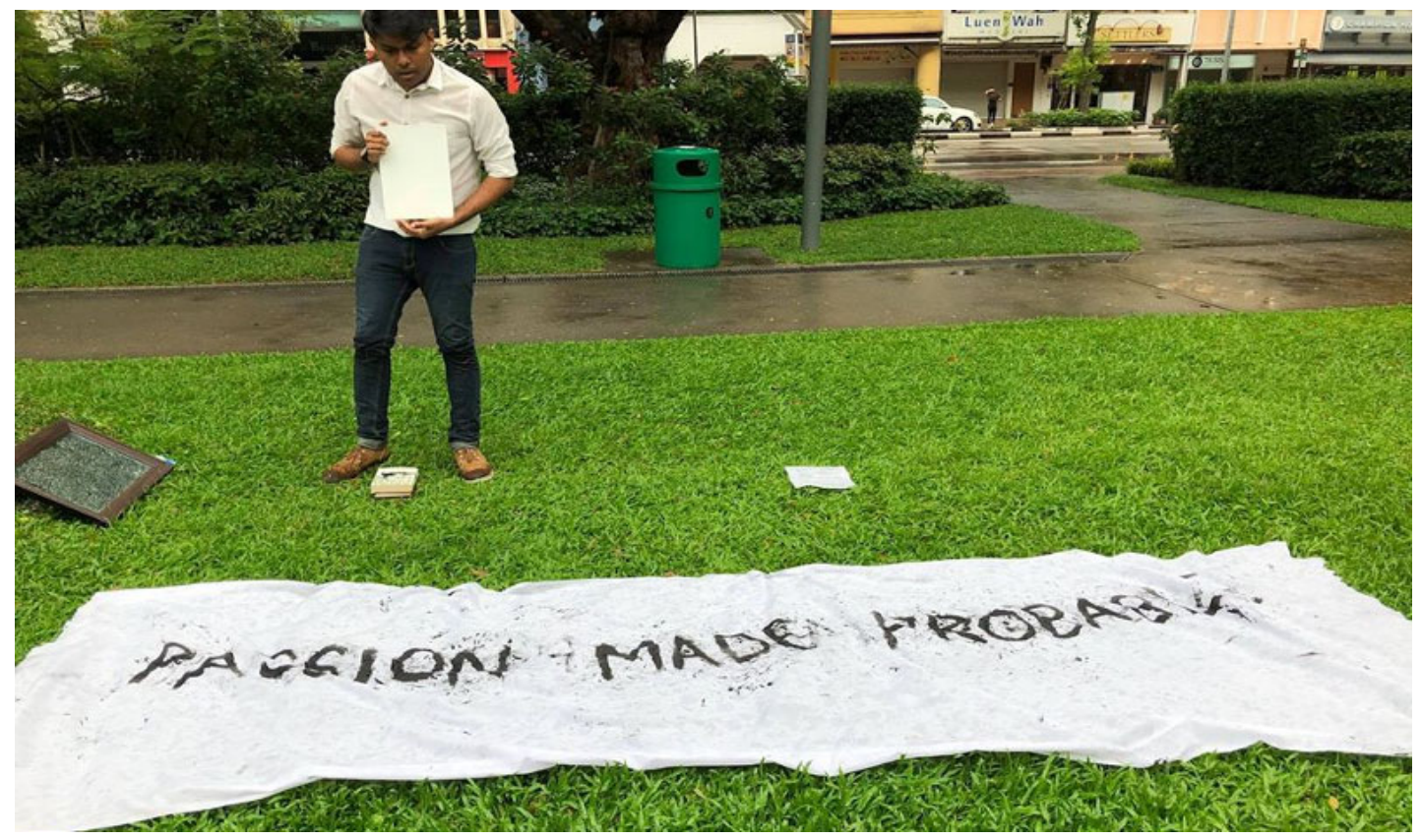

Figure 7. Courtesy, Seelan Palay at Hong Lim Park with banner during his performance 32 Years: The Interrogation of a Mirror, 2019.

32 Years: The Interrogation of a Mirror began in Hong Lim Park, commonly known as Speakers Corner, a designated public place in Singapore for permanent residents and citizens to lawfully demonstrate, hold exhibitions, and performances with the 
appropriate permit and registration with the authorities of their intentions. The online footage shows Palay unrolling a banner stating PASSION MADE PROBABLE. The slogan is a satirical response to Singapore's tourism slogan 'Passion made possible.' Palay asks the question, 'Can a liberated human mind be constrained by a state sanctioned space? A space in which you were contained, in that regard, can a liberated work of art be contained within a state sanctioned space? Do you know the answer to both of these questions? I will show you.' (Palay,2018). He then packs up his belongings and proceeds onto the streets. Palay explains that after Speakers Corner he first walked to the National Gallery of Singapore (Palay, 2019).

'When I concluded the first part (at Speakers Corner), I picked up the mirror and I walked out of the space, then I proceeded to the National Gallery of Singapore which used to be City Hall and is now the Supreme Court of Singapore. I draw symbolism from the relationship between the highest institution of state and law, and the highest institution of art, as both lack self-criticality.

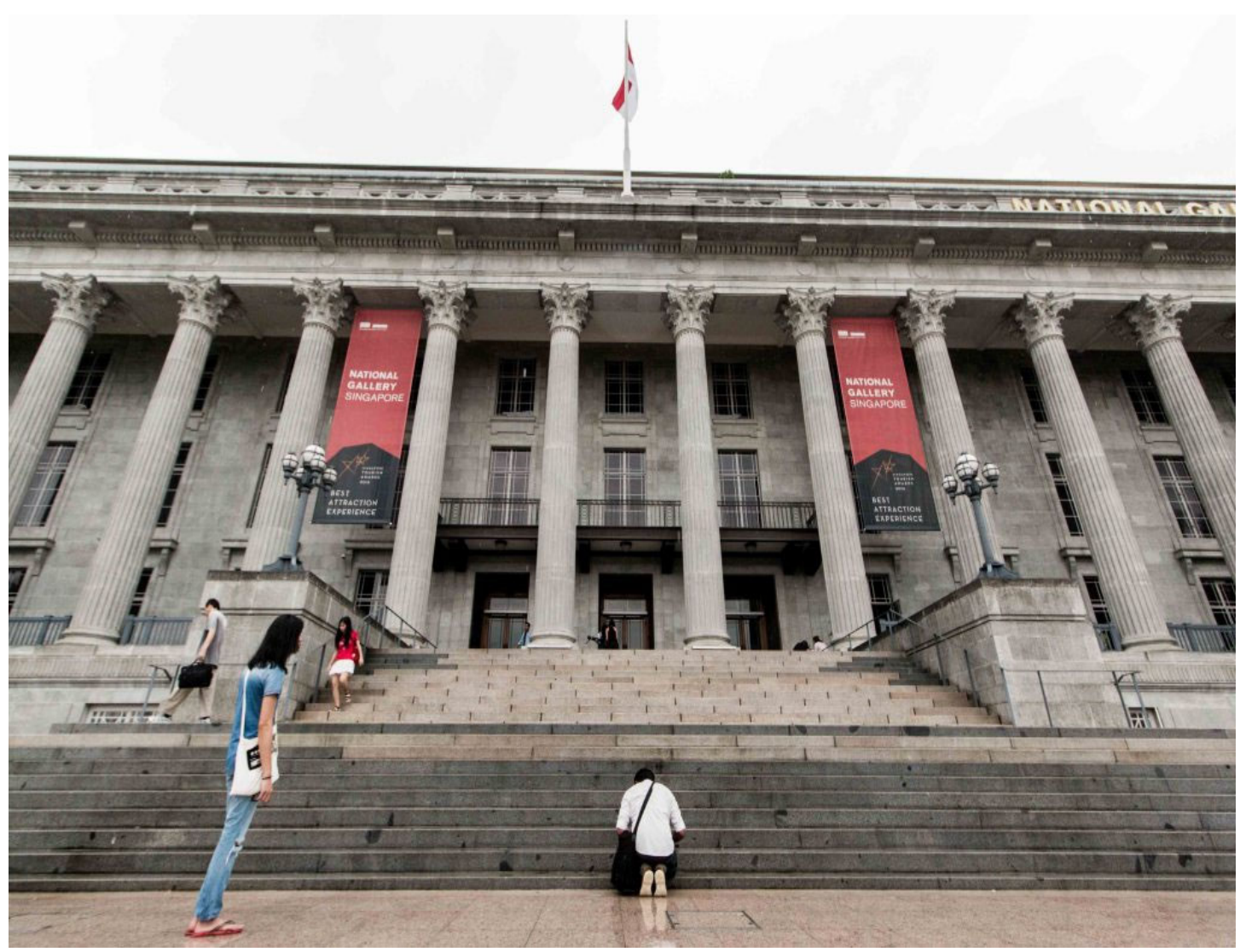

Figure 8. Courtesy, Seelan Palay outside the National Gallery of Singapore during his performance 32 YearsL The Interrogation of a Mirror, 2019.

At the steps I drew the entire façade, the pillars, the doors. I picked up the mirror and I walked up to the middle door, which I knew was locked. I stopped at the middle door, showed the mirror to the gallery without entering it, then turned around and proceeded to walk to Singapore's Parliament House. I drew the last drawing of the façade of the entire parliament house with flag on top. I showed the 
drawing in the direction of Parliament and I was prepared to stand there until $5 \mathrm{pm}$, but I was arrested at 4.15pm.'

Palay was charged and convicted under the Public Order Act, revealing how his performance art piece confronted the boundaries of citizen activity in the public realm and the streets as a place to enact authority. In this temporal intervention, Palay contested control over the public realm, revealing that the city and urban space is not neutral. The appropriation of public space for performance art engaged critically with hegemonic structures and highlighted how artists open discourses that embrace multiple perspectives.

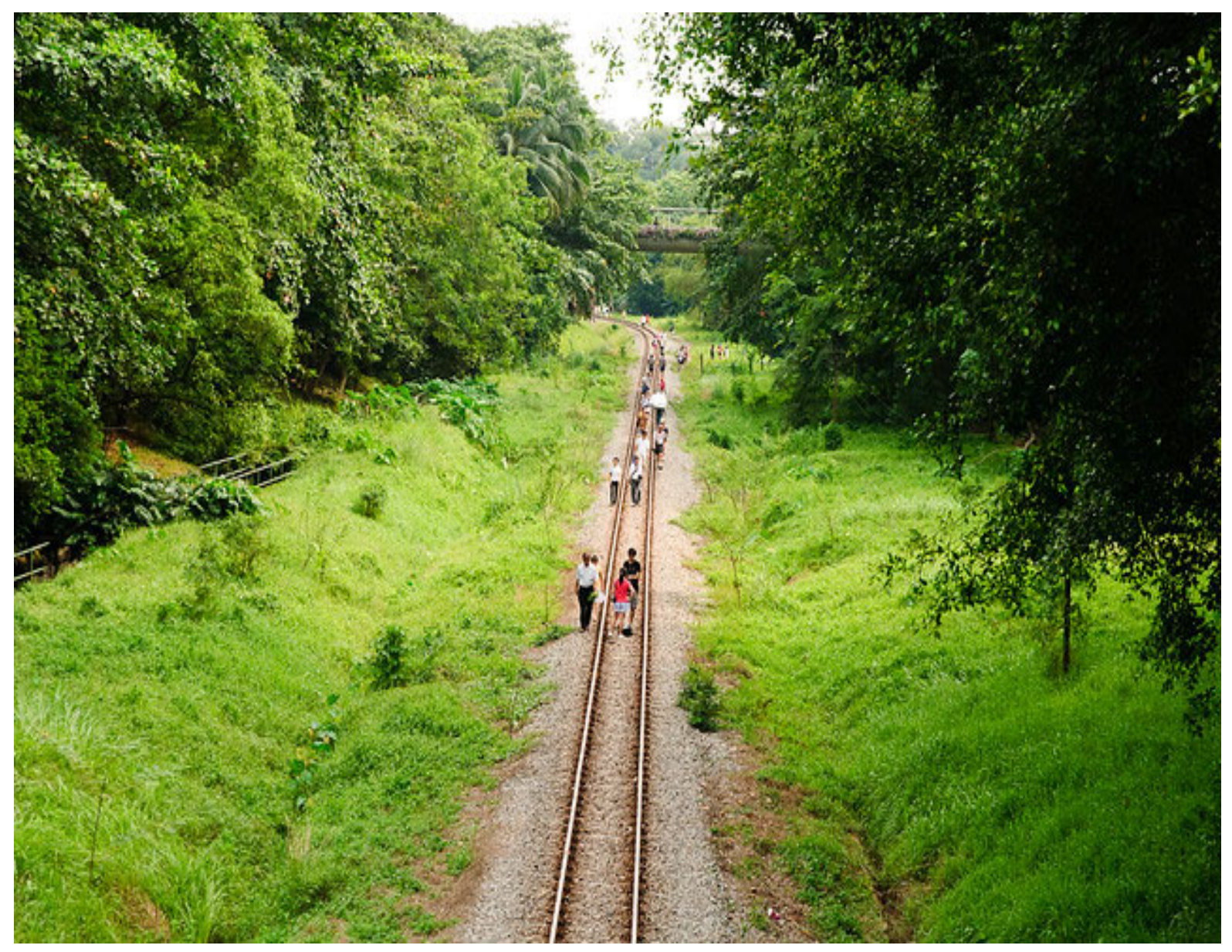

Figure 9. A view of walking group along the railway tracks from an overhead bridge near Blk I0, Ghim Moh Road, 201 I.

In Singapore, artistic approaches for engaging with public space and creating a dialogue driven by civil society also include projects that examine intersections of environment, culture and community. The Migrant Ecologies Project conceived and developed by educator, art writer, and artist Lucy Davis in 2009 combines research, adopts a collaborative framework and provides a platform for practice-led artistic inquiries into questions around community, public space, culture and nature. The Railtrack Songmaps Roosting Post I (2018) is an iteration of The Migrant Ecologies Project and 
explores the existing relations between humans and birds along the railway tracks of Tanglin Halt, an area which has flourished as public space that demonstrates how meaningful opportunities to shape, occupy and transform the public realm engages and delights citizens. However, the area is subject to social and environmental change as housing blocks are demolished and low-income residents are relocated elsewhere. (L. Davis, 202I).

The recording of bird calls undertaken by Davis is inter-twined with layers of song, story and images that also express the experiences of people and community living and using this area as told through interviews, films and text. Tanglin Halt is one of the first public housing development estates in Singapore. It runs along part of the former Malaysian railway tracks, which have been adopted for formal and informal activities including ecological walking and hiking, as well as, community gatherings, informal shrines and bird clubs. The tracks date to the British colonial period and comprise a major link between Singapore and Malaysia over many decades. The government opened the area for public use in $201 \mathrm{I}$ yet, commercial re-developments are beginning to encroach on the citizen led and activated area.

For The Railtrack Songmaps Roosting Post I (2018) Davis collaborated with an interdisciplinary team that included sound artist Zai Tang, video artist Kee Ya Ting, biologist David Tan and Tanglin Halt community members in partnership with the Nature Society of Singapore bird group. (Davis, 2018) 'Our search compiled over years of listening to birds and developing conversations with humans, reveal a rich seam of interspecies communications, projections, memories and songs.' Davis explains, 'Together with the Nature Society of Singapore Bird Group we compiled over 105 species of birds, resonating from what might appear on the surface to be an unremarkable patch of degraded, urban scrub.' Railtrack Songmaps Roosting Post I was presented in an HDB block of the Queenstown Residents' Committee Centre. This venue continued to broaden the opportunity for engagement by local residents with the project as active stakeholders, contributors and partners in the project, reflecting the positive ethos of community driven, citizen-led activated public space.

The possibility of community art projects to facilitate positive engagement between citizens is underpinned by the location of events, activities and exhibitions in public spaces. The performing arts company Drama Box, is a community theatre increasingly working in the public realm with community-based, arts driven approaches that are developed and presented in HDB buildings in partnership with Arts-wok Collaborative, a community development organization that harnesses art as a catalyst for opening up dialogue about difficult issues. Together they developed Both Sides Now, where artists develop long-term iterative projects in partnership with HDB residents around end-oflife issues. In addition to participatory and collaborative arts initiatives, the project organises puppet shows and other modes of theatrical and visual presentation that relate to issues about aging, death and dying, often in public spaces of HDB blocks. A recent iteration of this multi-year project was a public installation in the void deck of Block 7, Telok Blangah Crescent with spatial designer Wendy Chua and artists Alecia $\mathrm{Neo}$, anGie seah, Shirley Soh and Jasmine $\mathrm{Ng}$ who developed artwork with residents through transforming the void deck into a studio for video portrait workshops.

Activities present a participatory platform for communities to share and interpret their concerns and stories. These events bring people together in everyday public spaces as a way to expand and strengthen understanding and connectivity to their environment and, 
each other. At the same time, they enliven and animate public spaces through grassroots activities that enhance the collective qualities of the void deck. Initiatives such as Both Sides Now illustrate how void deck public spaces are ideal for encouraging connectivity between diverse groups, and encouraging active citizen participation. Drama Box, shares many characteristic of new genre public art, a term developed by the artist Suzanne Lacy to distinguish it in form and intention from 'public art', which is often used to describe sculpture and installations in public places. (Lacy, 1994)

'Unlike much of what has heretofore been called public art, new genre public art-visual art that uses both traditional and non-traditional media to communicate and interact with a broad and diversified audience about issues directly relevant to their lives -is based on engagement.' Lacy argues. 'Not specifically painting, sculpture, or film, for example, new genre art might include combinations of different media. Installations, performances, conceptual art, and mixed-media art, for example, fall into the new genre category, a catchall term for experimentation in both form and content. Attacking boundaries, new genre public artists draw on ideas from vanguard forms, but they add a developed sensibility about audience, social strategy, and effectiveness that is unique to visual art as we know it today... 'Art cannot be fully realized through monologue, it can only come into its own in dialogue, in open conversation in which one is obliged to listen and include other voices.'

Through engaging HDB residents in their homes and in the public spaces of the void deck, artists are finding ways to more fully engage the public in their immediate environment and participate in activities that also give them a voice to share their experiences and concerns. This work continues, and builds upon the tradition of informal activities occurring in these public spaces across Singapore.

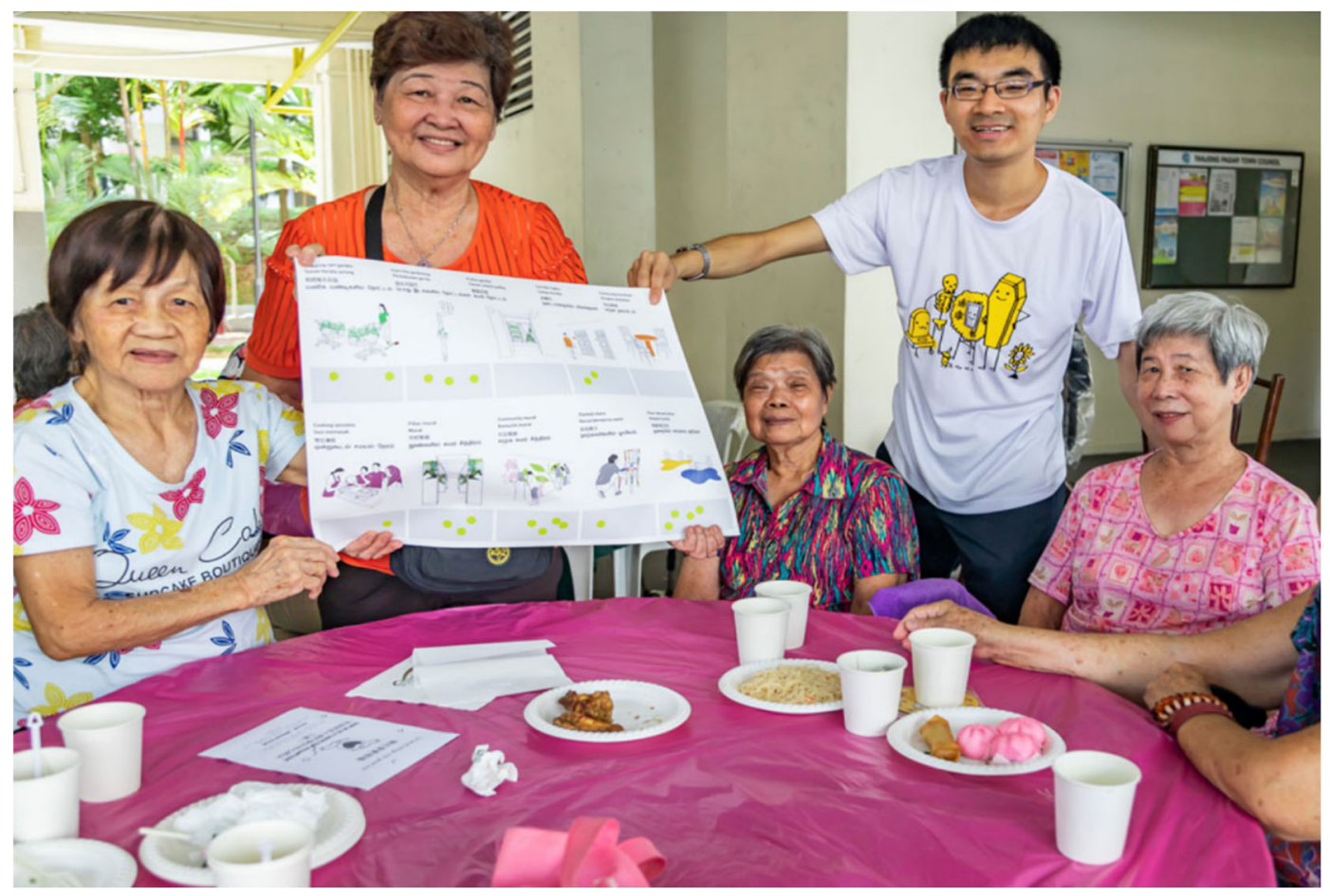

Figure 10. Drama Box Both Sides Now, Hello Parties at Telok Blangah, 2019. 


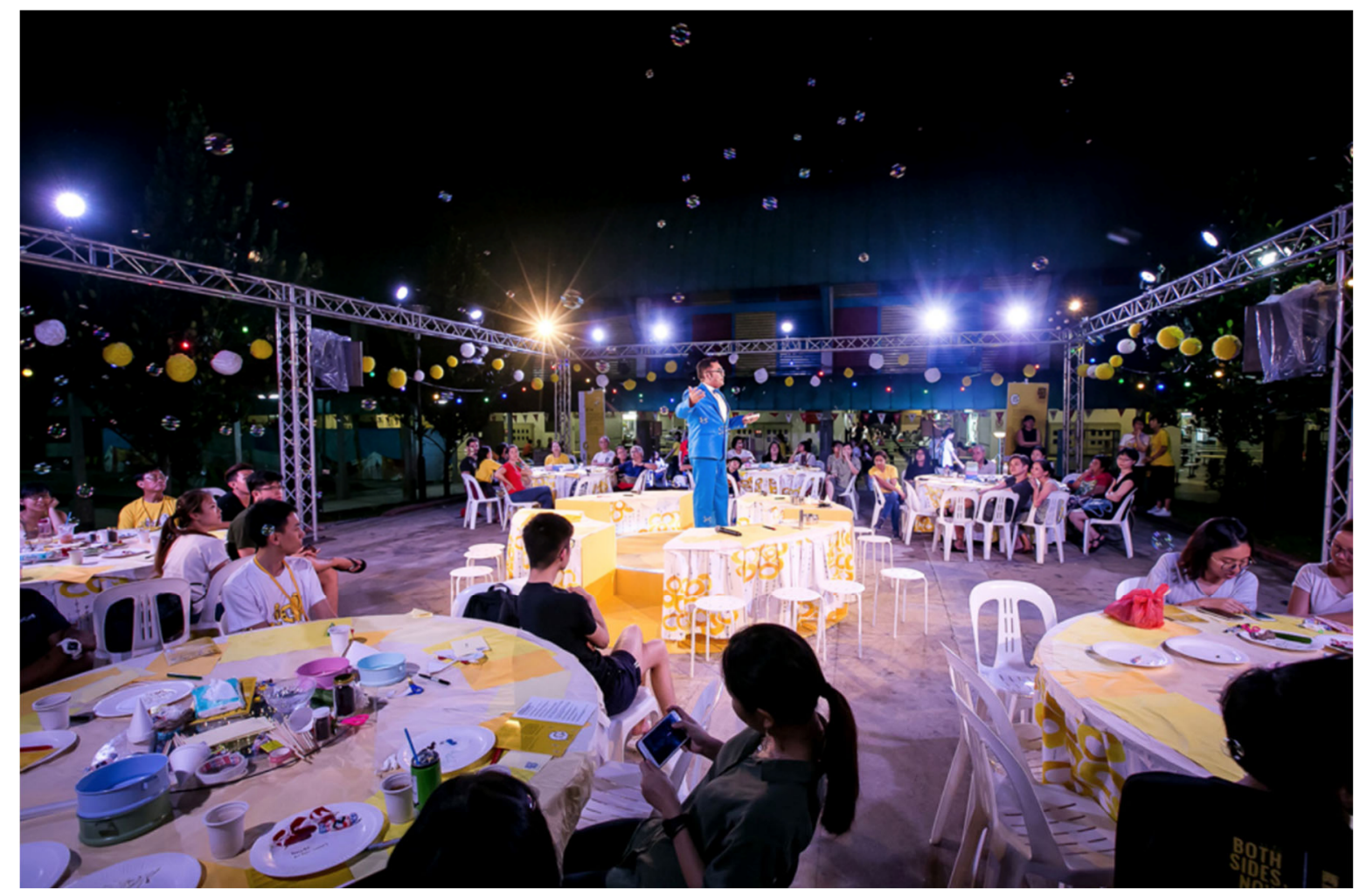

Figure I I. Drama Box Last Dance, Participatory Performance Telok Blangah, 2018.

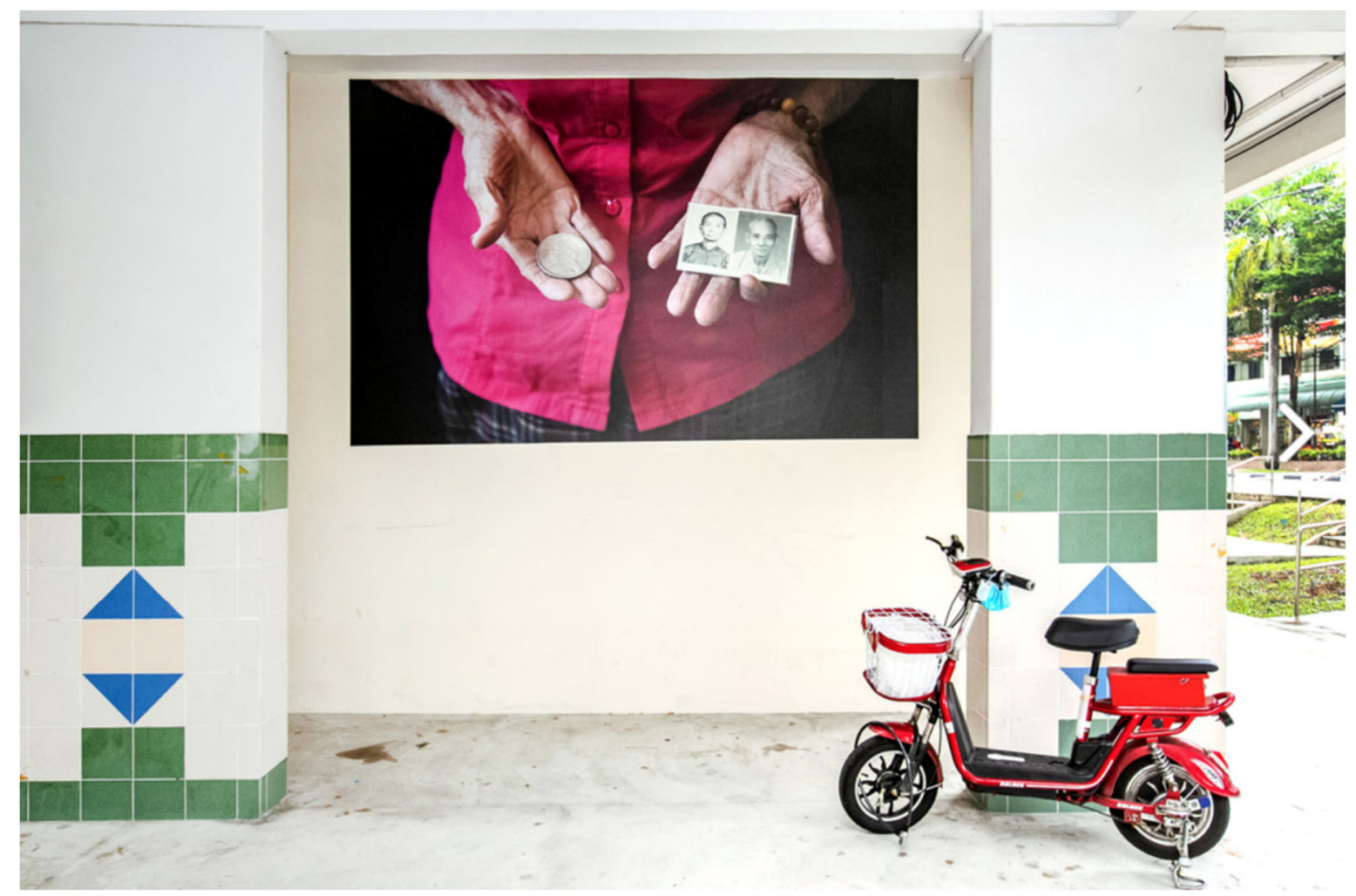

Figure 12. Drama Box, Closer - Public Art Installation, 19 September - 6 October 2018 at Chong Pang. 
Over the past decade, the future of land use in Singapore has led to public debate and interest in issues of spatial justice, and with the backdrop of ongoing redevelopment of the city, Singaporean not for profit spaces are leading engagement with themes of heritage, public space and ethical urbanism. Since 2017, The Substation, Singapore's first independent arts centre has engaged artists, thought leaders, field professionals and academics in a programme of exhibitions, events and discussions around the politics of power in the city intersect with public space, architecture and design. As part of The Substation's curatorial initiative, Discipline the City, the organisatino produced the publication 'A Public Square' edited by Adeline Chia in which she asserts how public space in Singapore is been threatened by privatization. 'The spaces around us, the pavements and the parks, the air-conditioned underground pedestrian linkages that are in fact extensions of malls, are all about power-vested interests of corporate interest and state control,' Chia writes. (Chia 2017, p, 6) This is observation is shared by Professor William S.W. Lim who cautioned against the dissolution of genuine public places that hold collective heritage, identity, memories and meaning. In his essay Public Space Today Lim foregrounds the impacts of losing public space for citizens. (Lim, 2014, Pp. I2- 13).

'With growing privatization such as themed shopping malls and corporate high rise offices and hotels many urban centres become luxury commodities that compete with each other by intense competition to attract foreign investments as well as the local and global cosmopolitan elites, 'Lim writes. 'These developments severely damage existing complex public spaces as they inevitably destroy much of the sensitive social linkages and heritage of gap spaces and the sites of critical deep histories that lie in the materiality of traditions.'

The importance of public space in preserving a collective sense of identity and role in sustainable development has been foregrounded in The Substation's 2018 exhibition Death-song, part of the 2018 curatorial framework, Cities Change, People Die, Everything you Know Goes Away an artistic investigation of a city where traces of the past constantly vanish and where conservation, identity and a sense of place are unstable. The exhibition highlighted the complex relationship between heritage, nostalgia and the narrative of progress, with works such as Triptych of the Unseen an installation and performance about Bukit Brown Cemetery, a site that became the subject of protest and civic engagement on issues of development and heritage after the Singapore Land Transport Authority approved plans to build an eight lane highway through the Cemetery, destroying an expansive area of nature and one of Singapore last primary forests, and at the same time exhuming 5000 tombs. This artwork and the public defense campaign of Bukit Brown highlights the high level of citizen engagement in concerns around spatial justice and the value ascribed to sustainable values around heritage and environment. The installation and performance Triptych of the Unseen (The Substation, 2018) occurred in three parts and with the help of cardboard goggles the audience joined spectral spectators to watch a performance by the Ghost, Activist and Bureaucrat, as three characters bound together through moral contradictions and entanglement in the contestation for space in the city. 


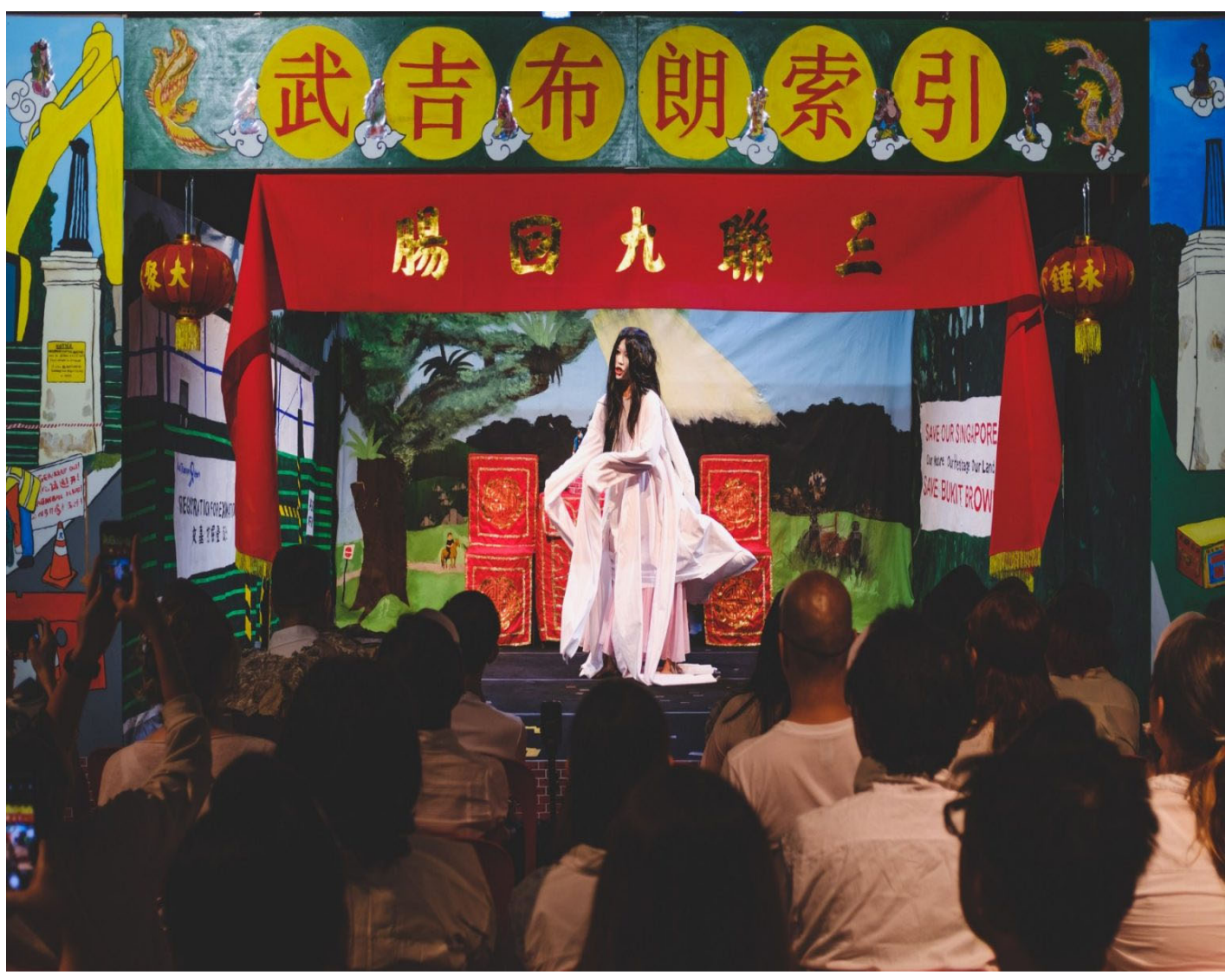

Figure 13. Bukit Brown Index \#132: Triptych of the Unseen Courtesy The Substation, 2018

Triptych of the Unseen was part of a broader project on Bukit Brown Cemetery initiated by the independent cultural and social enterprise, Post-Museum, founded by Woon Tien Wei and Jennifer Teo. The artists became intimately involved in the battle to retain Bukit Brown, first as part of the advocacy group SOS Bukit Brown, and then through their Intro to Bukit Brown a series of two hour afternoon walks that they conceptualized to engage visitors with the environmental and socio cultural heritage significance of Bukit Brown. The activity highlighted how artistic actions provide spaces for citizens to deepen their participation with the urban environment in a way that builds collective identity and historical connection. Post Museum produced a series of exhibitions including a wall documenting the names of exhumed and unclaimed grave sites which had to make way for the highway through Bukit Brown. This artwork was handwritten with assistance of volunteers and members of the public. For the artists Bukit Brown was a struggle over Singapore's soul, not only a sentimental conservation effort. (Tien Wei and Teo, 2016)

The transition from a model of individual authorship to one of collective relationships where art is collaboratively enacted in public space contributes towards diversifying audiences and creating new publics. 


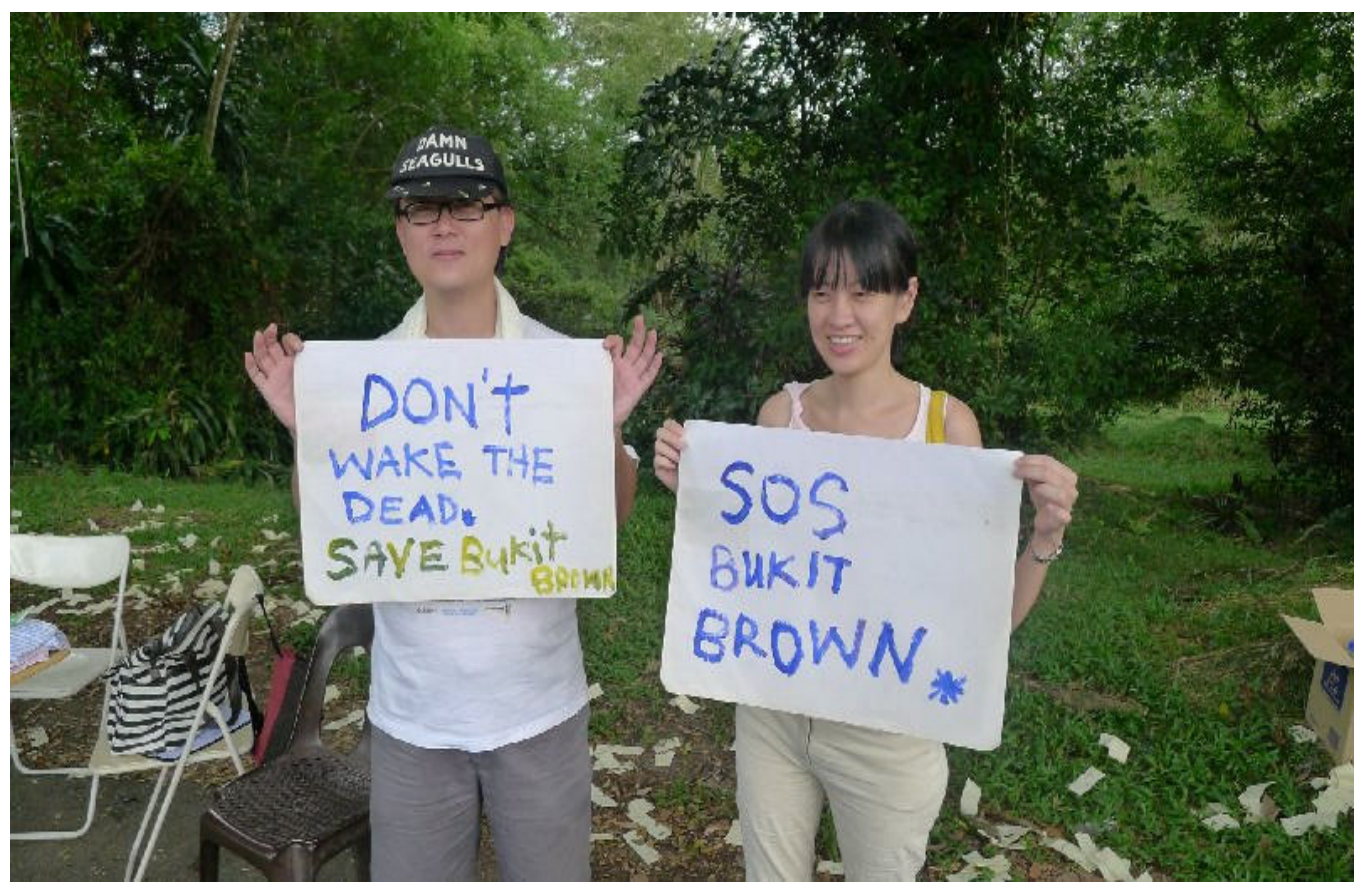

Figure 14. Citizens protesting as part of SOS Bukit Brown, Singapore

The case studies and projects described in this essay demonstrate the possibilities for a community of practitioners working across different mediums and disciplines, yet united by the common purpose of expanding notions of public space through artworks that are alternately activating, controversial and provocative, and delight and engage. Many art works offer new, exciting ways for connecting citizens, diverse communities and publics in activities that forge meaningful identity and belonging. Art in the public realm can create opportunities for forging conversations around spatial justice and highlight the value and benefits of genuine public space for citizens. The process of access, collaboration and engagement through artwork, and art activities in the public realm has created new pathways for the public to engage in positive acts of citizenship. In creating dissensus, the artists identified in this essay have an important role to play in expanding public spaces in the urban environment.

\section{References}

Amnesty International, 1998 Restrictions on Singapore's Longest Serving Political Prisoner Lifted, <https://www.amnesty.org/download/Documents/I52000/asa360061998en.pdf>

Chia, A. (2017) A Public Square, The Substation.

Chang T. C. (2020) Wall dressed up: Graffiti and Street Art in Singapore, City, Culture \& Society $(20)$.

Davis, L, The Migrant Ecologies Project, website viewed 20th June 2018 $<$ http://www.migrantecologies.org/>

Dia, Priyageetha, Interview (2018) Conducted by Sharmila Wood. 
Koh Zong Qi, 2018, Spacing Beyond the Lines: Grafitti's Place in the Singapore City-State National University of Singapore, Singapore.

Lacy, S. (1994) Mapping The Terrain: New Genre Public Art, Bay Press, Canada.

Lim, W. (20I4) Public Space in Urban Asia, World Scientific Publishing, Singapore.

McAuliffe, C. (2012) 'Graffiti or street art? : negotiating the moral geographies of the creative city', Journal of Urban Affairs, vol 34, no 2, pp 189 - 206.

Oh! Open House, Open House- Art In Your Home website viewed 20th October 2019 http://www.ohopenhouse.org/

Ranciere, Jacques, On Politics and Aesthetics,_Continuum International Publishing Group, 2010

Singapore Government (2019) Public Art Trust, website viewed 20th August, 2019 https://publicarttrust.gov.sg/

Speak Cryptic (2018) Speak Cryptic From the Streets at Art Science Museum, viewed IOth October 2019 <https://www.youtube.com/watch?v=CgE2uWWDt Q >

Tan A. (2019) The Artists Village: Openly Intervening in the Public Spaces of the City of Singapore, Open Philosophy 2:640-652

Tien W., W \& Teo, J, Post Museum website viewed $28^{\text {th }}$ June 2018

$<$ http://www.postmuseum.org />

Thompson, N. (2015) Seeing Power, Art and Activism in the 21 st Century, Melville House

Palay, Seelan. Interview (2018) Conducted by Sharmila Wood.

Wong, M. W. (2016) 'Performing Singapore's Queer Quandary: Walking the Tightrope Between Sexual Illegality and Neoliberal-Enabled Subjectivity at Pink Dot and in Loo Zihan's Cane', Queer Dramaturgies, Springer, pp. 66- 80. 